\title{
PRESENTACIÓN LIBRO DR. MARDONES
}

\author{
OBESIDAD ¿QUÉ PODEMOS HACER? \\ UNA MIRADA DESDE LA SALUD PÚBLICA
}

\author{
OBESITY ¿WHAT CAN WE DO? \\ A VIEW FROM THE PUBLIC HEALTH
}

Todos sabemos que la obesidad es un problema mundial. Según la Organización Mundial de la Salud, en el mundo existen 1000 millones de personas con sobrepeso y 400 millones con obesidad, y esta cifra se incrementa día a día.

El libro Obesidad ¿Qué podemos hacer? Una mirada desde la Salud Pública, enfoca el tema desde la perspectiva mundial y también nacional, con una puesta al día en un gran número de tópicos relacionados con la obesidad.

Para mi es muy grato presentar este libro editado por tres amigos, los Drs, Mardones, Rossowsky y Velasco. Con los tres me une un largo camino recorrido en los temas nutricionales, pero más que todo, me une un gran afecto.

Lo notable de este libro es la visión de Salud Pública que lo impregna y el principio básico que ha guiado la vida de los autores y que el Rector Rosso señala en su Prólogo como el leift motif de la Pontificia Universidad Católica de Chile: COMO DESDE LA INVESTIGACIÓN SE PUEDE DAR SOLUCIÓN A LOS PROBLEMAS NACIONALES. Esto ha sido también la directriz de la institución que dirijo, el Instituto de nutrición y Tecnología de los Alimentos (INTA) de la Universidad de Chile, que fue creado por el Dr. Fernando Monckeberg, precisamente con este mismo objetivo: como desde la investigación, poder derrotar la desnutrición.

Y por lo tanto, este libro muestra desde la evidencia científica lo que debe hacerse en políticas públicas. Quiero destacar, en este sentido, algunos aspectos que mas me llamaron la atención:

Por supuesto, me llamó la atención como desde las edades más precoces se puede prevenir la obesidad. Y agradezco a los autores la importancia que le dan al proyecto de Casablanca. En particular, me llamó la atención el acucioso análisis epidemiológico a la primera publicación que se realizó el 2005 en la Revista Chilena de Nutrición, sin grupo control, y como esto es posible de hacer de acuerdo a los criterios de Jean Pierre Habicht.

Cinco años después, puedo contar que en esto de traducir las evidencias en políticas hay tiempos y urgencias y el 2005 era urgente publicar estos resultados, aún cuando no se tuviesen los resultados del grupo control realizado en Quillota. Entonces me recordé de mi profesor en la Universidad de Cornell, Jean Pierre Habicht, y de una de sus publicaciones de 1999, en que señalaba la adecuación longitudinal para evaluar impacto, respecto de una línea de base, o sea, en términos sencillos, una evaluación "antesdespués", que se podía aplicar perfectamente al estudio. Con esto, nos decidimos a publicarlo inmedia- 
tamente, para iniciar un proceso de extensión de la experiencia de Casablanca a otras escuelas del país, lo que se ha conseguido mediante el programa NutriRSE de Acción Responsabilidad Social Empresarial, apoyadas por el sector privado, por las 1000 escuelas EGO del Ministerio de Salud, junto a otras escuelas de la JUNAEB.

Como anécdota, puedo contar 22 años después, que estando en Cornell en 1987, se constituyó un Comité de Búsqueda de Director de la División de Ciencias Nutricionales, en ese entonces el grupo académico nutricional mas prestigioso de los Estados Unidos y quizás también a nivel mundial. Después de un tiempo, la conclusión fue que la persona indicada era el Dr. Pedro Rosso, quién estaba por abandonar la U. de Columbia para venirse a Chile. Esto me llenó de orgullo, pero el Dr. Rosso prefirió retornar a su país, con los brillantes resultados por todos conocidos.

También me interesó mucho el capítulo de la Dra. Paula Margozzini y su tríada del riesgo: ObesidadSedentarismo y Tabaco. Fue precisamente con esta tríada, junto a factores psicosociales y ambientales, que se inició en 1998 la política de Promoción de Salud a través de VIDA CHILE. Esta política fue en respuesta al cambio del perfil epidemiológico que se había producido y que había quedado en evidencia con el primer estudio de Carga de Enfermedad realizado en 1995 y publicado en 1996.

Esta política de Promoción de Salud se inició con una capacitación intensa en todo el país a autoridades de los SEREMIs y Servicios de Salud en 3 módulos de dos días cada uno: un módulo era realizado por la Facultad de Medicina de la U. de Concepción: otro por el INTA y el tercero por el Departamento de Salud Pública de la Pontificia Universidad Católica, en el cual trabajamos con el Dr. Gonzalo Valdivia, en forma muy exitosa. Luego se continuó la capacitación a municipios y líderes comunitarios. Esta política, que se extendió a todas las Regiones del país y a 342 municipios, se fue diluyendo y pasó definitivamente a un segundo plano de las prioridades del Ministerio de Salud en los años 2004-2005, al ser el Plan AUGE la gran política ministerial en salud.

Otro tema interesante que plantea el libro, es el de la Dieta Mediterránea, y aquí quiero hacer un homenaje a mi amigo Federico Leighton por haber llevado este tema al conocimiento nacional, favoreciendo en gran medida el que la población vuelva a sus ancestros para tener una alimentación más saludable. Hace un año presenté un libro sobre Dieta Mediterránea en la Universidad de Talca, e hice el mismo reconocimiento. Aún cuando no hay resultados concluyentes de la relación dieta mediterránea/sobrepeso-obesidad, existe evidencia suficiente de que el consumo de verduras y frutas, que contienen mas de 5000 fitoquímicos positivos para la salud disminuye el estrés oxidativo y reduce el riesgo de obesidad y enfermedades crónicas. Esto ha motivado a la Organización Mundial de la Salud a promover el programa "5 al día" en el mundo, el cual se inició en Chile a fines del 2006 y que ha tenido gran impacto en el conocimiento de la necesidad de consumir frutas y verduras, sin que este conocimiento se haya transformado aún en un cambio de hábito en nuestra población.

En Chile se da la paradoja de que somos potencia alimentaria, país gran exportador de frutas y verduras, y la población consume menos de la mitad de lo que debería consumir. Notable es la mención que se hace mas adelante en el libro al tema de las ferias libres, que son lugares de encuentro muy importantes en nuestro país, o como dijo nuestro Premio Nacional Gabriel Salazar "espacios residuales de soberanía popular", donde se vende el $80 \%$ de las frutas y verduras que se consumen. Es por esto, que hoy día se está trabajando fuertemente con la Asociación Chilena de Organizaciones de Ferias Libres, la ASOF, para promover el consumo de frutas y verduras en el lugar de venta, con el conocido principio de que en el momento de la compra se decide lo que se consume en el hogar. 
El libro le da gran importancia a la actividad física como elemento protector de la salud y de prevención de la obesidad. Ambos, la alimentación saludable basada principalmente en el consumo de verduras y frutas, y la actividad física, son los pilares de la Estrategia Global contra la Obesidad o estrategia EGO, que se describe exhaustivamente en este libro.

Por último, existe un capítulo acerca de las ciudades saludables, de la intervención sobre el ámbito urbano y su impacto en la obesidad, con el ejemplo de Bogotá como una ciudad que de tener problemas muy graves, pasó a ser una ciudad modelo como saludable y vivible en el contexto de América Latina. Respecto al transporte activo integrado y las ciclovías, hay que hacer notar que la semana pasada fue enviada una Ley al Congreso de la República sobre este tema, basándose en la experiencia de Holanda.

Respecto a las experiencias internacionales, aparece nuevamente el ejemplo de Finlandia y por primera vez me toca conocer el de Corea del Sur. Respecto al ejemplo de Finlandia, que se considera paradigmático en estos temas, para su análisis es necesario establecer los dos parámetros fundamentales de la epidemiología: tiempo y espacio. Esta política se aplicó en la década del 70, en un país cercano a la Unión Soviética, que en esa época estaba bajo su influencia comercial, con una economía centralmente planificada, donde las directrices del nivel central se cumplían inexorablemente. Esto es muy diferente a lo que sucede en la década del 2000 en un país como Chile, que lleva más de 30 años de economía abierta, de libre mercado. Además, las tasas de mortalidad por enfermedades cardiovasculares de Finlandia en los 70, eran del orden de 500 por 100.000 habitantes. En Chile, nunca han sido superiores a 150 por 100.000 habitantes. O sea, tanto la realidad socio-política como epidemiológica (para no hablar de otras diferencias) eran y son muy diferentes a las de nuestro país. Por lo tanto, su aplicación a la realidad local chilena es difícil, por no decir imposible. Corea del Sur, en cambio, ha tenido una transición epidemiológica y nutricional semejante a Chile y sus políticas pueden ser más aplicables a nuestra realidad. Llama la atención el objetivo de su programa nutricional, que es promover la mantención de las tradiciones alimentarias, principalmente el consumo de arroz, vegetales y frutas, enseñando a valorar esta dieta y advirtiendo que los graves problemas que puede producir la dieta occidental.

Para terminar, e intentar una respuesta a la pregunta que titula el libro: ¿QUÉ PODEMOS HACER?, me permitiré una reflexión.

Chile tuvo un gran éxito al derrotar la mortalidad infantil y la desnutrición con un grupo preclaro de líderes, entre los cuales tiene un sitial importante el padre de Pancho, el Dr. Francisco Mardones Restat, al cual quiero rendir un homenaje hoy día, en que Don Pancho es el gran ausente. Don Pancho fue mi profesor, mi compañero de trabajo y mi amigo, al cual me unió un profundo cariño. Además de sus muchos méritos como salubrista, fue una persona excepcional desde todo punto de vista. El y muchos más, como los Drs. Abraham Horwitz, Jorge Mardones Restat, Sótero del Rio Gundián, los pediatras Meneghello, Rosselot, el Dr. Fernando Monckeberg y tantos otros, supieron convencer a diferentes gobiernos, a los políticos de la época y a la población en general, de la necesidad de tener programas financiados, continuos en el tiempo, con evaluaciones permanentes y por sobre todo, consensuados y apoyados por la comunidad científica, para derrotar la mortalidad infantil y la desnutrición.

En el caso de la obesidad, no hemos sido capaces de hacer que este tema sea prioritario ni que existan políticas nacionales, continuas en el tiempo, con respaldo financiero y legislativo. Se inició en 1998 una Política de Promoción de Salud sólida, consistente y coherente con la realidad epidemiológica del país, de amplia cobertura y apoyo poblacional, y a los pocos años se diluyó arrasada por políticas más inmediatistas del Plan AUGE. Hoy existen políticas dispersas en Promoción de Salud, sin la coherencia, 
respaldo ni prioridad suficientes, -como fue la que derrotó la mortalidad infantil y la desnutrición-, para enfrentar el gran problema que es hoy la obesidad.

Si no establecemos una Política de Estado única, coherente, continua en el tiempo, todos los esfuerzos que estamos haciendo, incluido este excelentemente bien editado libro, con toda la evidencia y políticas que plantea, habrán sido INÚTILES.

Ojalá que no nos suceda como a Isaías Fermín Fitzcarraldo, comerciante peruano, melómano y megalómano, que consumió su vida tratando de construir una nueva vía que comunicara la cuenca del Río Ucayali con los ríos Madre de Dios y Beni en el Perú, para lo cual hizo trasladar por tierra un barco a vapor a través del ahora llamado "istmo de Fitzcarraldo", además de tratar de construir un teatro de ópera en el Amazonas, como lo relata magistralmente el Director de Cine alemán Herzog en su película Fitzcarraldo y ahora en su reciente libro "La Conquista de lo Inútil", publicado por la Editorial Entropía el 2008, que se inicia con el siguiente diálogo de la película:

Fitzcarraldo: ¡Por el cocinero de sus perros!

$$
\text { ¡Por Verdi!, ¡por Rossini!, ¡por Carusso! }
$$

Don Araújo: ¡Por Fitzcarraldo, el conquistador de lo inútil!

Es de esperar que todos los esfuerzos que estamos haciendo para enfrentar el tema de la obesidad NO SEAN INÚTILES y se transformen en algo efectivo que mejore la salud, nutrición y calidad de vida de nuestra población. En ese sentido, el aporte de este libro en evidencias y políticas de lo que se puede y debe hacer, es y será fundamental.

Muchas gracias

Fernando Vio

Director INTA

Universidad de Chile 